NBER WORKING PAPER SERIES

\title{
INFORMATIONAL IMPERFECTIONS ON THE \\ CAPITAL MARKET AND \\ MACRO-ECONOMIC FLUCTUATIONS
}

Bruce Greenwald

Joseph E. Stiglitz

Andrew Weiss

Working Paper No. 1335

NATIONAL BUREAU OF ECONOMIC RESEARCH

1050 Massachusetts Avenue

Cambridge, MA 02138

April 1984

The research reported here is part of the NBER's research program in Taxation. Any opinions expressed are those of the authors and not those of the National Bureau of Economic Research. 
Informational Imperfections on the

Capital Market and Macro-Economic Fluctuations

\section{ABSTRACT}

This paper describes the role that informational imperfections in capital markets are likely to play in business cycles. It then developes a simple illustrative model of the impact of adverse selection in the equity market and the way in which this may lead to large fluctuations in the effective cost of capital in response to relatively small demand shocks. The model also derives an expression for the cost of equity capital in the presence of adverse selection and provides informational explanations for several widely observed macro-economic phenomena.

Bruce Greenwald

Harvard Business School

Boston, MA 02163
Joseph E. Stiglitz

Princeton University

Princeton, NJ 08544
Andrew Weiss

Columbia University

New York, NY 10024 


\section{INFORMATIONAL IMPERFECTIONS IN THE CAPITAL MARKET}

\section{AND MACRO-ECONOMIC FLUCTUATIONS}

Traditional neoclassical theory has one clear, unambiguous, and verifiable prediction: all factors which have a positive price are fully utilized. In recent years, there have been several responses to the apparent inconsistency between the predictions of neoclassical theory and what has in fact been observed. The first is to deny the empirical observations: the $25 \%$ of the population that were unemployed in the Great Depression, let alone the $10 \%$ of the population that were unemployed in the Reagan Recession were not involuntarily unemployed. This seems to us, at best, semantic quibbling, and we shall have nothing further to say here concerning that view. The second is to argue, without much justification, that there are two regimes; traditional neoclassical theory applies in "normal times." It seems more plausible to us that the market failures represented by the Great Depression are always present in the economy, but difficult to detect; it is only when they reach the proportions that they do periodically that we can no longer ignore them.

A third approach is to modify the standard theory, to assume that wages and prices are fixed. This approach has rightfully been criticized both for its ad hocery and its inconsistency--why should rational profit maximizing firms, obeying all of the other neoclassical assumptions, not cut their prices in the face of excess demand.

This paper is part of an attempt to develop a consistent set of microfoundations for macro-economics, based on imperfect information. We focus here on the capital market. Keynes argued that the sharp drop in investment and the failure of the interest rate to fall sufficiently to restore investment to a normal level was a central part of the description of any business cycle. Reynes' analysis of investment was, however, basically a neoclassical analysis: it was 
the failure of the real interest rate (the long-term bond rate) to fall sufficiently that was the source of the problem.

Three aspects of this analysis have always been troubling: first, Keynes' explanation of the fallure of real interest rates to fall, the liquidity trap, is not persuasive. Second, surveys suggest that firms' investment behavior is not particularly sensitive to the interest rate that they pay. Third, it has always seemed difficult to account for the magnitude of the fluctuations in investment in terms of the observed magnitudes of variations in real interest rates, outputs, wages, and prices, unless firms are very risk averse; and it is hard to reconcile high degrees of risk aversion on the part of firms with well-functioning (neoclassical) capital markets.

This paper is based on the hypothesis that Keynes" judgment concerning that the importance of fluctuations in investment is correct, but that he incorrectly analyzed the determinants of investment behavior. We argue that:

1. Many firms face credit constraints; thus it is the availability of credit, not the price which they have to pay, which restricts their investment, or when it is working capital which is curtailed, which limits their production.

2. Firms that are not credit constrained may still face an increase in the effective cost of capital, which induces them to reduce their investment. (The increase in the effective cost of capital has further effects, e.g., on the pricing decisions of firms.)

\section{The Debt Market}

The main informational problem facing banks is that they do not know how the money they lend is being invested. Stiglitz-Weiss $(1981,1983)$ showed that an increase in the interest rate charged borrowers will, in general, increase the average riskiness of the projects a bank is financing. This is either because borrowers switch to riskier projects or because safer projects become relatively 
less attractive and so investors with safe projects do not apply for loans. The effect on the riskiness of loans may outweigh the direct gain to the bank from increasing its interest rate. Thus, the bank's profit may be maximized at an interest rate at which there is an excess demand for loanable funds.

This kind of phenomenon (an interior price maximum and rationing, which may also occur in the labor market) helps to explain business cycles in three ways. First, and most obviously, it provides a rationale for the persistence of non-market-clearing. Second, it may account for variations in a firm's cost of capital which are unrelated to observed variations in interest rates. The likelihood and severity of credit rationing may well increase in a recession without necessarily any concurrent change in interest rates. An increase in credit rationing might be expected both because of greater uncertainty concerning the prospects of firms and an increase in the dead-weight loss associated with bankruptcy. Third, information-based rationing models can explain how stabilization policy is likely to work. For example, monetary policies which seek to increase investment by lowering interest rates will not have the desired effect: there is no shortage of willing borrowers. However, policies that increase the avaiIability of loanable funds will increase investment, even though they may not affect the level of interest rates at all.

There are two objections to our credit rationing theory as an explanation of the cyclical fluctuations in investment. First, why don't firms that face credit constraints from banks attempt to raise capital by some other means, in particular, by issuing new equity. And second, many firms that do not appear to be credit constrained also seem to reduce their investment dramatically. Thus, a necessary complement to the theory of credit rationing is a theory of informational imperfections in equity markets. This we present in the next two sections. 


\section{Equity Markets}

A firm's ability to raise equity capital is limited by informational imperfections for two basic reasons. First, incentive problems may intensify when a firm is equity financed. Managers, who receive only a small fraction of any additional profit, are likely to put forth less-than-optimal amounts of effort. Imposing large bankruptcy costs on managers may act as a spur to added effort and the value of these incentives is reduced by additional equity finance. Debt financing also allows managers less flexibility in disposing of net income than equity does. Thus, equity funds may reduce the value of a firm by allowing more "profit" to be diverted to the private uses of the firm's managers. Finally, lenders have the power to discipline managers by withdrawing their funds. This is a sanction which can be imposed piecemeal and may, therefore, be more effective than share voting to which majority rule applies. 1

Second, signalling effects may restrict a firm's access to equity markets. Managers of firms, which they know to be "good," may be willing to assume greater debt burdens. Both the absolute level of bankruptcy risk and any incremental increase due to added debt will be smaller for "good" than for "bad" firms. Greater reliance on debt by "good" firms means that equity will predominantly be sold by inferior ones (see Ross (1977)). Thus, attempting to sell equity may convey a strong negative signal about a firm's quality and reduce its market value accordingly.

The model presented in this paper analyzes the cyclical cost of capital implications of the signalling process just described as an example of the macroeconomic impact of the many limitations on equity issue which are noted above. It provides an explanation for large, but not directly observable, variations in the marginal cost of capital (to be distinguished from the average cost of capital measured for example by Tobin's q) which can account for many of the variations in investment which are commonly associated with business cycles. The negative 
signal associated with issuing equity means that the cost of equity is prohibitive for many firms. Thus, the effective marginal cost of capital is the marginal cost of debt which consists of the monetary cost of interest plus the marginal increase in expected bankruptcy cost associated with additional debt. The latter bankruptcy cost will increase as a firm faces unexpectedly adverse economic conditions and may do so dramatically. Moreover, it is likely that the adverse signal associated with issuing equity will intensify and place equity finance even further out of reach in just these circumstances.

III. A Simple Model

In this section, we construct a simple model which enables us explicitly to determine which investors will make use of the equity market and which of the debt market, and which enables us to calculate the effective marginal cost of capital. Because we wish to focus on the equity market, we assume bankers can perfectly discriminate among borrowers - indeed, the function of banks is to differentiate potential borrowers into their appropriate risk classes - but that the equity market treats all those seeking equity the same. (Thus, while Stiglitz-Weiss (1981) were concerned with imperfect information in the credit market, we are concerned here with imperfect information in the equity market. In a sequel, we investigate a more general model incorporating both.) We make the following assumptions:

(A1) Each firm is characterized by a net cash flow, $\theta$, from existing operations and a set of new investment opportunities whose return is $\varepsilon_{Q}(R)$, where $\varepsilon$ is a r.v., $E(\varepsilon)=1, \operatorname{Var}(\varepsilon)=\sigma_{\varepsilon}^{2}$ and $\mathrm{K}$ is the level of investment. ${ }^{2}$ For expositional reasons, although firms are assumed to have different levels of $\theta, Q(\cdot)$ is assumed to be the same for all firms. The parameter $\theta$ describes the "quality" or "value" of a particular firm and has a distribution $N(\theta)$ across firms. ${ }^{3}$ 
At the beginning of the period firms announce their equity sales intentions and $V_{o}$, each firm's market value, adjusts accordingly. Firms then sel1 (or do not sell) equity, determine the level investment and finance any uncovered balance with debt. At the end of the period, the results of new investment are determined, some firms go bankrupt, and the values of $\theta$ are revealed for the remaining firms. The terminal value of each firm's equity is determined based on its observed value of $\theta$. Managers' compensation depends on current market value and the share of terminal market value held by original shareholders, if the firm does not go bankrupt. In the event of bankruptcy managers bear a known fixed cost.

Assuming risk neutrality, the firm acts as if it maximizes,

$$
T=m V_{0}+(1-m)\left(\frac{V_{0}}{V_{0}+e}\right)(\theta+Q(K)-b(1+R))-\mathbf{c P}_{B},
$$

where,

$$
\begin{aligned}
& \mathrm{b}=\mathrm{K}-\mathrm{e} \equiv \text { level of new borrowing, } \\
& \mathrm{R} \equiv \text { Expected return on debt, } \\
& \mathrm{C} \equiv \text { Cost which "bankruptcy" imposes on a firm's managers, } \\
& \mathrm{P}_{\mathrm{B}} \equiv \text { Probability of "bankruptcy," } \\
& \mathrm{m} \equiv \begin{array}{l}
\text { Factor describing the weight that firms place on their } \\
\text { initial as opposed to their terminal market value. }
\end{array}
\end{aligned}
$$

(A2) "Bankruptcy" occurs if,

$$
\theta+\varepsilon Q(K)<\left(1+R_{0}\right) b \text {, }
$$

where $R_{0} \equiv$ Contractual rate of interest on a firm's debt
$>R_{\text {. }}$

(A3) Lenders are fully informed, risk neutral and require an expected return $R$,

$$
(1+R)=\left(1+R_{0}\right)\left(1-P_{B}\right)+\int_{0}^{\varepsilon} 0\left[\frac{\theta+\varepsilon Q(K)}{b}\right] d F(\varepsilon)
$$


where $\varepsilon_{0}=\left[\left(1+R_{0}\right) b-\theta\right] / Q(K) \equiv$ the value of $\varepsilon$ below which "bankruptcy" occurs.

(A4) Equity investors are risk neutral and require an expected return $R$. They observe only the level of a firm's equity sales in determining $v_{0^{*}}$ Firms selling equity sell a common dollar amount $\mathrm{e}_{\mathrm{o}^{\circ}}$

The information structure of the model may appear restrictive, but in fact is quite general. Allowing equity investors to observe only the level of equity sales is a matter of interpreting the model as applying to a set of firms whose other observable characteristics are identical. The analysis need only be replicated for each such class of firms to cover the full firm population. 4,5

A firm's equity sale decision rule can be characterized by examining the function,

$$
H(\theta) \equiv T^{D}(\theta)-T^{E}(\theta),
$$

where,

$$
\begin{aligned}
& \mathrm{T}^{\mathrm{D}} \equiv \mathrm{mV}_{\mathrm{o}}^{\mathrm{D}}+(1-\mathrm{m})\left(\theta+\mathrm{Q}\left(\mathrm{K}^{\mathrm{D}}\right)-\mathrm{K}^{\mathrm{D}}(1+\mathrm{R})\right)-\mathrm{cP}_{\mathrm{B}}^{\mathrm{D}}, \\
& v_{0}^{D} \equiv \text { Initial value of firms selling no equity, } \\
& K^{D} \equiv \text { Optimal level of investment for a non-equity selling } \\
& \text { firm of quality } \theta \text { (the } \theta \text { argument has been supressed), } \\
& \mathrm{P}_{\mathrm{B}}^{\mathrm{D}} \equiv \text { Level of bankruptcy risk implied by the optimal } \\
& \text { investment decisions of a non-equity issuing } \\
& \text { firm (again the } \theta \text { argument has been suppressed), } \\
& T^{E} \equiv m V_{0}^{E}+(1-m)\left(\frac{V_{0}^{E}}{v_{0}^{E}+e_{0}}\right)\left(\theta+Q\left(K^{E}\right)-\left(K^{E}-e_{0}\right)(1+R)\right)-c P_{B}^{E} \text {, }
\end{aligned}
$$

$\mathrm{V}_{0}^{\mathrm{E}}, \mathrm{K}^{\mathrm{E}}$ and $\mathrm{P}_{\mathrm{B}}^{\mathrm{E}}$ are defined analogous $1 \mathrm{y}$ to $\mathrm{V}_{0}^{\mathrm{D}}, \mathrm{K}^{\mathrm{D}}$ and $\mathrm{P}_{\mathrm{B}}^{\mathrm{D}}$. Assuming that $\varepsilon_{0}$ lies in the lower tail of a single peaked $\varepsilon$ distribution, it is relatively straightforward to show that $d H(\theta) / d \theta>0$. Thus, the optimal decision rule for individual firms on equity sales policy is the following,

$$
e^{*}= \begin{cases}e_{0} & \text { if } \theta \leq \hat{\theta} \\ 0 & \text { if } \theta>\hat{\theta}\end{cases}
$$


where $\hat{\theta}$ is defined by $H(\hat{\theta})=0$. Given equation (4) firms entering the equity market will be adversely selected. And, although in this simple model an equilibrium always exists, it may be one with zero equity sales. However, if $\theta \geq 0$ for all firms and $m$ is close to zero, then an equilibrium with positive equity sales will exist. In such an equilibrium, $v_{0}^{E}$ is determined by the equation,

$$
v_{0}^{E}=\frac{1}{N_{E}} \int_{0}^{\hat{\theta}}\left(\frac{\theta+Q\left(R^{E}\right)}{1+R}-\left(K^{E}-e_{0}\right)\right) N(\theta) d \theta-e_{0},
$$

where

$$
N_{E}=\int_{0}^{\hat{\theta}} N(\theta) d \theta
$$

It is relatively easy to show that the resulting equilibrium level of $v_{0}^{E}$ has the following properties under suitable regularity conditions on $F$,
(i) $\frac{\mathrm{dv}_{\mathrm{o}}^{\mathrm{E}}}{\mathrm{dc}} \geq 0$
(ii) $\frac{\mathrm{dV}_{0}^{\mathrm{E}}}{\mathrm{dm}} \leq 0$
(iii)
$(1+R) \frac{\mathrm{dV}_{\mathrm{o}}^{\mathrm{E}}}{\mathrm{dR}} \geq 0$

In each instance an increase in $\mathrm{V}_{0}^{\mathrm{E}}$ is associated with an increase in the number of firms issuing equity (a decrease in $V_{0}^{E}$ is associated with a decrease in the number of firms issuing equity).

Also, if $N(\theta)$ is normal with variance $\sigma_{\theta}^{2}$, then, $\mathrm{dV}_{0}^{\mathrm{E}} / \mathrm{d} \sigma_{\theta}^{2} \leq 0$

The optimal investment condition which characterizes non-equity issuing firms is, 6

$$
Q_{k}=(1+R)\left[1+\left(\frac{c}{1-m}\right)\left(\frac{f_{O}^{D}}{1-P_{B}^{D}}\right)(1 / Q)\left(1-\left(\frac{K \cdot Q_{k}}{Q}\right)\left(1-\frac{\theta}{K(1+R)}\right)\right)\right],
$$

where, $f_{0}^{D}$ is the level of the $\varepsilon$ density function at $\varepsilon_{0}^{D}$, where $\varepsilon_{0}^{D}$ is the level of the $\varepsilon$ for a non-equity issuing firm at which, when $K$ is optimally chosen the firm defaults ( $\varepsilon_{0}^{D}$ depends, of course, on $\theta$ ). The second bracketed term on the righthand side of (5) represents the component of the cost of capital attributable to 
the marginal increase in the risk of bankruptcy. As $\theta$ falls (because a negative demand shock reduces the value of existing cash flows), this term may rise dramatically as $f_{0}^{D}$, and $P_{B}^{D}$ increase. 7

Any such increase is limited ultimately by the possibility of issuing equity. However, equity issue becomes a viable alternative only when the following condition holds,

$$
\begin{aligned}
c\left(\frac{P_{B}^{D}-P_{B}^{E}}{e_{0}}\right) & +(1-m)(1+R) \frac{v^{E}(\theta)-v^{D}(\theta)}{e_{0}} \\
& =m\left(\frac{v_{0}^{D}-v_{0}^{E}}{e_{0}}\right)+(1-m)(1+R)\left(\frac{v_{0}^{E}}{v_{0}^{E}+e_{0}}\right)\left(\frac{v^{E}(\theta)}{v_{0}^{E}}-1\right)
\end{aligned}
$$

where $V^{D}(\theta)=\left((\theta+Q(K)) /(1+R)-K^{D}\right)$ which is the market value of a firm of quality $\theta$, whose level of investment is optimal for debt finance (given $\theta$ ), assuming that $\theta$ were observable. $v^{E}(\theta)$ is defined analogously with $k^{E}$ replacing $K^{D}$. The left-hand side of equation (6) represents the differential benefits of equity finance per dollar of equity. This consists of the reduced level of bankruptcy risk and the benefits of an increased level of investment (i.e., $\left.V^{E}(\theta)-V^{D}(\theta)\right)$. The right-hand side of equation (6) captures the differential cost of issuing equity. It consists of a signalling cost (the first term on the right-hand side of (6)), embodying the difference in the value of a firm which results from issuing equity (divided by the amount of equity issued), plus a dilution cost (the second term on the right-hand side of (6)) which arises because a firm with a true value $\mathrm{V}_{0}^{E}(\theta)$ must sell equity as if it had a value $v_{0}^{E}$.

In practice, the "effective" cost of issuing equity may be so high as to be prohibitive. Event studies (most recently Asquith and Mullins (1983)) indicate that an equity issue announcement reduces the value of a firm by about 3 percent. And this may be a substantial underestimate since it is based on firms who actually issue equity and who are, as a result, likely to have the lowest cost of 
doing so. Thus, if $m=\frac{1}{2}$ and a new equity issue amounts to 5 percent of a firm's outstanding stock, the signalling cost of equity will, by itself, amount to more than 30 percent. It is not surprising, therefore, that firms rarely issue equity. Moreover, if strong firms enjoy an enhanced advantage over weak ones in the face of adverse economic conditions, a negative economic surprise will increase the dispersion of $N(\theta)$ and increase the cost of issuing equity just when it is most needed. 8

IV. Concluding Remarks

Informational imperfections have a fundamental effect on the functioning of the capital market. In some circumstances, competitive markets will be characterized by credit rationing: it is the avallability of capital and not its cost that determines the level of investment. Here, we have provided an explanation for why firms whose credit is constrained do not avall themselves of the equity market. And we have shown that the effective marginal cost of capital for those who are not constrained is not simply related either to the real long-term interest rate (as Keynes' hypothesized) or to the price of equity (as more recent portfolio theories have argued); the effective marginal cost of capital may experience much larger cyclical fluctuations than either of these variables. These variations in the effective cost of capital in turn play an important role in explaining observed patterns of cyclical behavior regarding both investment and prices.

Although the former effect is obvious, the latter may not be. When current prices affect not only present but future demand (see Phelps and Winter (1970)), firms will maximize profits with a price at which short-run marginal costs lie above short-run marginal revenues. The gap is filled by the contribution of lower prices to future profits. Under these circumstances, an increase in the cost of capital reduces the present value of any future market position and 
will lead to an increase in current prices. Our cost of capital view leads to just such a conclusion; as a recession begins, this tendency toward higher prices might well counteract the effect of falling demand and account for some price stickiness. In this and other ways informational imperfections may provide a consistent economic explanation for many hitherto unexplained aspects of macroeconomic behavior. 


\section{FOOTNOTES}

1. There are well-known impediments, both theoretical and practical, to shareholder control whether mediated via takeovers or normal corporate governance.

2. For simplicity, existing net cash flows are assumed to be certain. Making existing cash flows uncertain would merely complicate the analysis and reinforce the basic results.

3. The model, as presented, involves only a single period but can be easily extended to a sequence of periods with independent $\theta$ draws in each period.

4. The restriction to discrete levels of equity sales, though made primarily for expositional convenience, has certain important theoretical justifications and consequences.

5. In order that each class include firms with more than a single value of neither $K$ nor $b$ may be perfectly observable to equity investors. However, given current accounting conventions and the timing of debt reports this is not implausible.

6. A similar condition would apply for equity issuing firms because they are limited to issuing only $e_{0}$ dollars of equity. This is an artifact of our assumptions.

7. As $\theta$ declines, the term $\left(1-\left(\frac{K \cdot Q_{k}}{Q}\right)\left(1 \frac{\theta}{K(1+R)}\right)\right)$ decreases, partially offsetting the impact on the marginal cost of capital of the factors cited above. However, this effect is in large measure an artifact of the simple way in which uncertainty is embodied in the model. If $\varepsilon$ affects both $\theta$ and $Q(k)$, then the corresponding term in the resulting expression for the marginal cost of capital tends to increase as $\theta$ declines.

8. The dilution cost also rises under these circumstances as $V_{0}^{E}$ falls relative to $\mathrm{V}_{0}(\theta)$. And, as $\mathrm{v}_{0}^{\mathrm{E}}$ falls, the cost of raising $e_{0}$ dollars of equity embodied in the factor $\left(V_{0}^{E}\right) /\left(V_{0}^{E}+e_{0}\right)$ rises. 


\section{$\underline{\text { BIBLIOGRAPHY }}$}

1. Asquith, Paul and Mullins, David W. "Equity Issues and Stock Price Dilution," unpublished paper, Harvard Business School. November 1983.

2. Phelps, Edmund S. and Winter, Sidney G. "Optimal Price Policy under Atomistic Competition" in Microeconomic Foundations of Employment and Inflation Theory, Edmund S. Phelps, ed., W.W. Norton and Co., New York, 1970.

3. Ross, Stephen A. "The Determination of Financial Structure: The Incentive Signaliing Approach," The Bell Journal of Economics, Spring 1977, 8, 23-40.

4. Stiglitz, Joseph E. and Weiss, Andrew. "Credit Rationing and Markets with Imperfect Information," American Economic Review, June 1981, 71, 393-411.

5 .

and

"Incentive Effects of Terminations: Applications to the Credit and Labor Markets," American Economic Review, December $1983,73,912-927$. 